\title{
Metodologias participativas no ensino da administração em Enfermagem
}

Carmen Elizabeth Kalinowski ${ }^{1}$ Reinaldo Miguel Dolny Massoquetti ${ }^{2}$

Aida Maris Peres ${ }^{3}$

Liliana Müller Larocca ${ }^{4}$ Isabel Cristina Kowal Olm Cunha ${ }^{5}$

Luciana Schleder Gonçalves ${ }^{6}$ Riciana do Carmo Calixto

\section{Introdução}

O trabalho docente requer competência pedagógica na mobilização e articulação de diferentes saberes para motivar o estudante a assumir responsabilidade ou corresponsabilidade no processo de aprendizagem. Para tal, optou-se pelo uso de metodologias significativas e participativas por proporcionarem oportunidades para a articulação do trabalho docente com as necessidades do estudante.

As metodologias significativas possibilitam a exploração de saberes dentro de um contexto particular, valorizando conhecimentos e experiências anteriores, envolvendo os alunos na identificação e busca de soluções para situações vivenciadas por eles nas atividades que compõem o processo educativo, o que favorece a atuação efetiva do estudante no processo pedagógico (Vannuchi, Campos, 2007).

A aprendizagem significativa pode ser definida, segundo Tavares (2004), como a oferta de um novo conhecimento estruturado de maneira lógica; a existência de conhecimentos na estrutura cognitiva que possibilite a conexão com o novo conhecimento, bem como a atitude explícita de apreender e conectar o conhecimento com aquele que pretende absorver.

Para o docente, trabalhar com metodologias significativas é transpor e superar o uso de metodologias tradicionais, embasadas na transmissão de informações ou conhecimentos com resultados reconhecidamente insatisfatórios para entender e atuar na realidade. Nessa nova proposta metodológica, são criadas oportunidades para a vivência dos discentes em experiências que representem as diferentes situações cotidianas em saúde, com o desafio de transformá-las em práticas educativas significativas e que possibilitem a construção reflexiva e crítica do discente (Martínez-Riera et al., 2011; Teofilo, Dias, 2009).

Entende-se que, nas metodologias participativas, o docente assume o papel de construtor de possibilidades para a aprendizagem. Estas consistem em criar, a partir de situações reais do trabalho em saúde, práticas educativas que permitam a vivência e aprendizado do discente em situações concretas problematizadas. As práticas educativas com metodologias participativas possibilitam, aos envolvidos no processo de aprendizagem, a articulação entre um conhecimento prévio e um 
novo. Essa articulação facilita o processo de elaboração e diferenciação do conhecimento, ou seja, aprender a partir do que se conhece (Leite, Prado, Peres, 2010; Moreira, 1999).

As estratégias mais utilizadas nas metodologias significativas e participativas, e que atendem a este envolvimento, são as de trabalho em grupo, jogos dramáticos, dramatizações, entre outras, que pressupõem a importância da vivência do estudante em grupo e que a condução da aprendizagem ocorre pelas inter-relações vivenciadas no processo, ditadas pelo próprio tempo e ritmo dos seus componentes. O grupo motiva o indivíduo e o indivíduo motiva o grupo; o indivíduo aprende com o grupo e o grupo com ele, assim, há destaque de que é importante a alternância entre trabalho individual e em grupo (Leite, Prado, Peres, 2010).

A dramatização, ou drama, é "um gênero misto entre a comédia e a tragédia" (Ferreira, 2010, p.266). Dramatiza-se com a necessidade da crítica à sociedade, de compreender os processos que se vive, para poder viver.

Tobase, Gesteira e Takahashi (2007, p.216-7) discorrem sobre a dramatização como "uma estratégia que confere significados aos conteúdos ensinados". Ao contrário do método tradicional de ensino, com o qual se espera que o conteúdo ensinado seja o conteúdo apre(e)ndido, o uso da dramatização propõe que os conteúdos ensinados sejam experimentados pelos discentes com: o pensamento do contexto sociopolítico-econômico-cultural, a espontaneidade, o desafio de transpor limites teóricos e a oportunidade de enfrentar a resolução de problemas reais na sociedade, em sua organização atual, ligando a aprendizagem proporcionada pela experiência com os conteúdos ensinados. Discentes mencionados pelas mesmas autoras demonstraram satisfação em aprender e compromisso em exercitar diferentes papéis no universo profissional na área da saúde.

A dramatização é um jogo de papéis que dá significado aos conteúdos, propõe a experimentação, pelos estudantes, com a realidade do trabalho em saúde, vivenciando diferentes papéis na relação profissional, com as atribuições e atividades em saúde, como permite uma análise crítica reflexiva no enfrentamento de situações reais, permitindo criar novas possibilidades de soluções ou arranjos técnicos aos mesmos (Ruiz-Moreno, 2004).

O jogo de papéis, que a dramatização possibilita, pressupõe assumir uma função social que não é a sua, facilita a compreensão das atitudes e decisões do outro, e treina habilidades necessárias e requeridas para, no presente caso, o trabalho em saúde; permite também que o próprio grupo elabore gradualmente uma história para que papéis ou personagens sejam incorporados. A elaboração gradual da história é mediada por um coordenador, papel do docente que, pelo uso de outras técnicas, facilita e conduz o processo. A técnica não permite, ao docente, o controle do ensino como no método tradicional. Sua participação, além do conduzir o processo de criação, é a relação final do produto com os temas estudados. Favorece, aos estudantes, a oportunidade de vivenciarem e compreenderem determinadas situações do trabalho em saúde (Souza, 2007).

Pode-se compreender, também, a dramatização como o resultado de um grupo, do diálogo e da pluralidade de ideias orientados pela criatividade e pela sensibilidade. As concepções são importantes e devem ser discutidas, pois o grupo sempre existe, mesmo que apenas uma pessoa conceba, planeje, produza, elabore e apresente, haverá a plateia para a qual se apresentará. A criatividade se estabelece como capacidade de que ideias discutidas ou postas pelo grupo sejam modificadas, visando a adaptação ao resultado esperado. O docente não controla a dramatização, tal como controlaria a aplicação do método tradicional de ensino, ele é transformador daquilo que a dramatização oferece para algo efetivo na aprendizagem (Souza, 2007).

Estudiosos no assunto colocam as três modalidades da estratégia de dramatização mais utilizadas no processo de ensino: o sociodrama/psicodrama, que prioriza e permite avaliar a interação e as relações no grupo; o role playing, ou jogo de papéis, que possibilita, aos envolvidos no processo de ensino, assumirem um papel social que não é o seu; e a oficina de educação em saúde, metodologia voltada para ações de educação em saúde articulada com a cultura da comunidade (Leal, Nova, 2009; Souza, 2007; Tobase, Gesteira, Takahashi, 2007; Brasil, 2001).

O sociodrama é teorizado para que o enfoque esteja no grupo, em suas inter-relações, ou seja, há uma dependência de um e de outro pertencente ao mesmo grupo. O psicodrama é teorizado para se avaliar a interação de um com o grupo, conferindo a ele a responsabilidade de compreender e atuar 
sobre suas comédias e tragédias da vida. Ao retirar o constituinte psicológico-terapêutico, a compreensão da dramatização como sociodrama/psicodrama se dá por um problema do grupo, evidenciado por métodos de ação (Souza, 2007; Tobase, Gesteira, Takahashi, 2007).

O role playing é considerado como jogo de papéis, porque implica assumir um papel social que não o seu, para que se elabore, gradualmente, uma história para esse papel, ou personagem. A elaboração dessa história é mediada por um coordenador, que aprovará ou reprovará a história elaborada gradualmente. A proposta busca facilitar a compreensão das atitudes e decisões do outro no jogo, em que um assume o papel do outro (Rodrigues, 2004). Os discentes assumem os papéis de outros para treinar suas habilidades.

A oficina de educação em saúde é apresentada, dentro de programas governamentais brasileiros (Brasil, 2001), como metodologia de educação com foco na intervenção social em saúde. As oficinas valorizam a identidade cultural local, tecendo-a com o agregado de processos que diferenciam um grupo de outro, com o interesse principal de ter produtos finais palpáveis com o uso das artes (cênicas, plásticas, visuais, musicais), propagandas (cartazes, panfletos, cartilhas e outros) e publicidades (divulgação da iniciativa).

Neste estudo, a opção definida foi a do role playing, por permitir aos estudantes criarem a partir de um conhecimento construído e por meio da arte de representar, vivenciar e perceber, pelo olhar do personagem, as questões relacionadas à situação e às intervenções do trabalho em saúde. A elaboração da história é mediada por um docente, que conduzirá o grupo para que o texto elaborado represente a realidade, permita o processo educativo e facilite a compreensão das atitudes e decisões de todos envolvidos, treinando habilidades e competências necessárias para o trabalho em saúde.

O estudo tem como objetivo relatar a experiência de docentes da área de administração e gerência em saúde no processo de aplicação e avaliação de uma prática de aprendizagem participativa, com discentes do Curso de Graduação em Enfermagem, na disciplina de Planejamento e Administração em Saúde.

\section{Desenvolvimento da experiência}

Atividade educativa, desenvolvida, no segundo semestre de 2010, com: 23 estudantes cursando a disciplina de Planejamento e Administração em Saúde, em um Curso de Graduação em Enfermagem, na cidade de Curitiba; quatro docentes; cinco enfermeiras de diferentes serviços relacionados à assistência à saúde da mulher, de um município da região metropolitana de Curitiba, e um discente monitor. Foram três meses de construção, preparação, desenvolvimento, aplicação e avaliação da prática educativa.

Às docentes coube a escolha das temáticas de planejamento em saúde, funções gerenciais e Sistema Único de Saúde - SUS, com ênfase na organização e a operacionalização do sistema. Ressaltase que todas compõem o universo de temas desenvolvido na disciplina de Planejamento e Administração em Saúde. A seguir, foram definidas e organizadas as estratégias de ensino, com foco no trabalho em grupo e role playing. O grupo de docentes, entendendo a necessidade de mudança do seu papel para facilitadoras do processo, elaborou e discutiu as atividades que conduziriam os discentes na aprendizagem; avaliou e percebeu as necessidades de mudanças no processo em conjunto com os discentes, e proveu os recursos necessários para o desenvolvimento das ações.

As temáticas planejamento em saúde, funções gerenciais e SUS, com ênfase na organização e sua operacionalização, foram desenvolvidas por meio do estudo dos programas da Política Nacional de Atenção Integral à Saúde da Mulher (pré-natal, parto, mulher vítima de violência, câncer de mama e câncer de útero) e do Programa de Humanização no Pré-natal e Nascimento, com o olhar no conhecimento sobre a gestão dos serviços de saúde e a gestão das práticas dos profissionais em saúde, especialmente da equipe de enfermagem, acrescido e articulado ao conhecimento prévio dos discentes na prática clínica do cuidado de enfermagem. O ensino das práticas clínicas - como a consulta do enfermeiro, as intervenções de enfermagem que abordam as dimensões da promoção, prevenção, assistência e reabilitação - foi desenvolvido em semestre anterior, o que foi considerado, pelas docentes, como um facilitador, por terem, os discentes, o domínio prévio desses saberes. 
O estudo dos programas de saúde foi realizado na estratégia de trabalho em grupo. Foram constituídos cinco grupos, por escolha livre dos discentes, tanto para a composição de cada grupo quanto para a escolha do programa a ser estudado. Cada grupo se responsabilizou por um dos programas e realizou pesquisa nos documentos na biblioteca virtual em saúde localizada no portal virtual do Ministério da Saúde e em outros, oficiais e gratuitos. Para esta prática, cada grupo recebeu um roteiro orientador sobre quais informações e conhecimentos deveriam reconhecer nos referenciais localizados, bem como a descrição de situações problematizadas relacionadas à saúde da mulher que os ajudassem a compreender o trabalho em saúde e o da enfermagem, com ênfase no papel e atribuições do enfermeiro.

Com estes novos conhecimentos, elaboraram um roteiro para uma visita técnica a serviços relacionados à assistência à saúde da mulher, em um município da região metropolitana de Curitiba, com o propósito de compreender a organização e a gestão do sistema, assim como a gestão do trabalho em saúde. Importante destacar que, nesta disciplina, a multiprofissionalidade e a intersetorialidade do trabalho em saúde são discutidas com os discentes. Estes percebem a relação e interdependência das práticas de cuidado de enfermagem com as dos demais profissionais de saúde, como, também, com outros setores (educação, social, entre outros) importantes para a busca de possíveis resoluções para algumas situações-problema em saúde.

A seguir, cada grupo elaborou e entregou um relatório sobre esta atividade, que foram apresentados em um encontro com as docentes e enfermeiras responsáveis pelos serviços visitados. A apresentação proporcionou um debate construtivo e reflexivo, permitindo a percepção e avaliação positiva sobre a construção e/ou a inserção de novos conhecimentos. Segundo os próprios discentes, eles conseguiram aprofundar, compreender e reconhecer: a organização do SUS, a relação entre as diferentes práticas profissionais em saúde e, sobretudo, que o envolvimento e o compromisso foram determinados pelo grupo e pelos seus componentes.

Para o processo de consolidação dos conhecimentos tratados e a possibilidade de exercitarem as funções gerenciais (planejamento, coordenação, direção e avaliação), o grupo foi desafiado a realizar uma apresentação com a modalidade da dramatização role playing.

Inicialmente, as docentes se reuniram com os discentes escolhidos para formarem o grupo diretor, para apresentação e discussão sobre o resultado esperado nesta atividade. A proposta de role playing teve como fundo temático a história de vida de uma família e sua relação com os serviços sociais, relatados em um estudo de caso. Os discentes tiveram orientação sobre a técnica do role playing e foram disponibilizados artigos que tratavam do presente assunto.

Um segundo encontro, agora com todos os 23 discentes matriculados na disciplina, foi para discutir e refletir sobre a técnica do role playing e o estudo de caso com a história a ser representada. A seguir, o grupo diretor procedeu à apresentação do planejamento dos trabalhos e à organização dos alunos. Para tal, a turma foi organizada em três subgrupos: um responsável pela elaboração do roteiro, com oito discentes; um responsável pela sonoplastia e iluminação, com seis componentes; e um responsável pela divulgação, com três discentes. O grupo diretor definiu atribuições e metas para cada grupo, solicitou que cada grupo elaborasse um plano de ação, definisse seu coordenador e estabelecesse um cronograma de encontros.

O grupo responsável pelo roteiro conduziu uma reunião com todos para: fomentar ideias e sugestões para a composição do texto final; sugestões para cenário, figurino, e a definição dos discentes-atores. Foi exitoso ao aplicar a dinâmica de "chuva de ideias". Percebeu-se que a maioria dos discentes contribuiu para a possibilidade de construir um texto denso, com riqueza de situações e propostas de intervenções em saúde.

A técnica e a condução do encontro possibilitaram a vivência de duas das funções gerenciais: coordenação e direção de maneira lúdica, agradável, porém real. Os discentes perceberam que a responsabilidade final retornou ao grupo do roteiro, que assumiu o compromisso de construir o roteiro, sua atribuição nesta etapa da prática. O roteiro final foi apresentado e aprovado pela docente responsável. O trabalho em grupo prescinde deste processo de ir e vir: momentos do pequeno grupo com sua tarefa, momentos de apresentação e aprovação por todos os envolvidos. 
O estudo de caso relatava a história de vida de uma família, com ênfase em saúde da mulher, e, também, nas relações com os vínculos familiares, no contexto do cotidiano familiar, na comunidade, e na relação com os diferentes serviços sociais; continha breves relatos de uma gestante hipertensa e com antecedentes obstétricos de aborto; seu esposo com problemas de alcoolismo e violência doméstica. Também apresentava a mobilização da comunidade e a relação com outros movimentos sociais; os recursos sociais na comunidade - escola, creche, projetos sociais, entre outros; e finalizava com um breve relato sobre a organização da saúde na comunidade, a unidade de saúde, seus recursos e ações em saúde disponíveis para a comunidade.

Importante ressaltar que o estudo de caso permitia, aos discentes, o acréscimo e/ou o detalhamento de situações em saúde ou sociais, bem como as intervenções em saúde necessárias. Foi um instrumento utilizado com maestria pelos discentes, com criação e demonstração do conhecimento apreendido ao elaborarem o texto final que, efetivamente, abordou situações reais do cotidiano familiar, dos serviços de saúde e da relação destes com os outros serviços sociais necessários para o encaminhamento das questões abordadas. Os discentes canalizaram a oportunidade de perceber como o indivíduo se insere no Sistema de Saúde a partir de problemas de saúde reais identificados.

As docentes perceberam que o conhecimento das temáticas de administração - foco deste relato foi apreendido pelos discentes, por apresentarem situações não só do cuidado individual ou coletivo, mas de gerenciamento ou nas dimensões individuais ou coletivas, de relação organizacional da atenção à saúde, demonstrando que os problemas em saúde não são isolados ou iguais, porém o tratamento, aos indivíduos e grupos, deve respeitar a individualidade e a coletividade. Essa reflexão surgiu por causa do embasamento teórico dos temas abordados, ou seja, a estruturação do roteiro a partir do estudo de caso.

O grupo responsável pelo cenário, figurinos e sonoplastia desenvolveu um plano de ação para viabilizar os recursos necessários para a apresentação, como: arrecadar material para figurino, cenário; conseguir autorização para o uso dos equipamentos e materiais de saúde existentes no laboratório de enfermagem do curso. O grupo criou um fundo musical, com músicas de autores brasileiros que cantam histórias parecidas com a do estudo de caso. O cenário foi uma composição de equipamentos e projeções de figuras com diferentes espaços que retratavam a história.

Posteriormente, houve um momento em que se discutiu que o conhecimento tratado na prática foi entrelaçado com outros conhecimentos que não são de domínio ou objeto de estudo do curso; mas a vivência pessoal e do grupo em transitar em outras áreas de conhecimento possibilitou a criatividade e ludicidade, importantes neste processo de aprendizagem.

O grupo da divulgação, além de cartazes colocados no Setor de Ciências da Saúde da universidade, convidou os discentes, especialmente os ingressantes do curso. Em relação aos enfermeiros dos serviços visitados e docentes, o grupo encaminhou convite individual e à equipe. Preparou um programa do dia da apresentação, com sinopse da peça, e da atribuição de cada discente, que foi entregue a todos os ouvintes.

O grupo diretor acompanhou e realizou os encontros com a presença de responsáveis de cada grupo e, sistematicamente, repassava as informações às docentes, mas não necessariamente todas, criando expectativa, própria da estratégia adotada, demonstrando a possibilidade de provocar, também no docente, a curiosidade, importante para o processo avaliativo.

A apresentação aconteceu em sala de aula, que foi organizada em dois espaços distintos, um destinado à apresentação e um aos convidados. Os convidados, em torno de cinquenta, foram recepcionados pelos grupos diretor e de divulgação. A apresentação, com duração de uma hora, foi extremamente rica em situações que abordaram todos os programas da saúde da mulher estudados e as questões sociais inseridas no texto. A inserção, na peça, de situações do cotidiano que permeiam a assistência de enfermagem na Atenção à Saúde da Mulher e a gestão pública, permitiu também aos discentes raciocinarem sobre as funções gerenciais no roteiro.

Após a apresentação, os discentes diretores coordenaram um debate articulando as temáticas, esclarecendo dúvidas, sobretudo dos discentes ingressantes, e envolvendo todos na discussão, apoiados pelas docentes presentes.

Os discentes ingressantes no curso, que, no período, discutiam as áreas de atuação do enfermeiro, avaliaram que a apresentação permitiu concretamente entender o trabalho do enfermeiro, 
compreendendo as práticas profissionais do enfermeiro nas dimensões assistencial e gerencial. Também apontaram a importância de conhecerem um pouco sobre a organização do SUS.

Uma questão ressaltada, no momento do debate, pelos dois grupos de discentes - ingressantes e cursantes da disciplina - foi a reflexão sobre o trabalho do enfermeiro, seja como cuidador ou como gestor do cuidado. Considerou-se que as possibilidades de cuidar são inúmeras e diversificadas, que há importância de o trabalho em saúde ser multidisciplinar e interdisciplinar, e que as situações em saúde vão para além da competência técnica, necessitam da competência de comunicação para se articularem intersetorialmente.

A avaliação da atividade foi conduzida pelo grupo diretor a partir de um roteiro proposto pelas docentes, com questões relacionadas à modalidade definida, role playing, e às temáticas. O grupo acrescentou outras questões relacionadas ao processo de condução da turma. O encontro foi coordenado e dirigido pelo grupo no dia seguinte e com respostas satisfatórias sobre o processo de aprendizagem. O momento de apropriação e consolidação das práticas das funções gerenciais, um dos destaques da avaliação, revelou que a atividade permitiu a todos exercitarem as quatro funções gerenciais, com variações e formas de trabalhar diferentes entre eles. Em outro momento de apropriação do conhecimento, reconheceu-se a individualidade e as diferenças. A estratégia permitiu o exercício das funções gerenciais em uma situação real, concreta e com significado para todos.

A presença de convidados e dos discentes ingressantes foi positiva, porque os discentes atores se preocuparam em representar com exatidão e clareza as situações, permitindo a compreensão do trabalho do enfermeiro, foco do outro grupo de discentes, que, em uma situação real e problematizada, puderam debater a profissão que escolheram. Avaliaram que, além da aplicação das funções gerenciais, conseguiram compreender um pouco mais sobre o SUS e que há muito, ainda, a aprender sobre este tema. Entenderam que foram introduzidos de uma forma aprazível a serem defensores deste sistema.

Em outro momento, as docentes conduziram a avaliação da prática educativa inteira, desde os estudos dos programas em saúde até a apresentação. Foram apontadas a viabilidade e a efetividade do aprendizado com o uso de metodologias participativas, e destacado que requerem tempo e mobilização de recursos, especialmente por parte dos docentes e dos discentes, e destes últimos, um deslocar para ser um participante ativo e compromissado.

\section{Considerações finais}

As docentes destacaram que a construção de práticas de aprendizagem com metodologias participativas requer tempo, motivação, dedicação e comunicação, mas, sobretudo, a mudança do seu processo de trabalho. Envolver-se, acompanhar os discentes em diferentes tempos e lugares é uma das exigências, pois o processo de aprendizagem não acontece exclusivamente na sala de aula ou nos espaços previamente determinados pelos docentes, como o relato demonstrou.

Requer do docente uma atenção aos diferentes discentes ou grupos de discentes que estão em momentos diferentes do processo de aprendizagem. Exige, também, planejamento detalhado e acurado destes momentos, e habilidade de adaptação, seja das estratégias ou dos papéis que o docente assume ao utilizar metodologias participativas.

O docente passa a ser um dos membros do grupo envolvido no processo, com funções determinadas, sendo a principal a de ser um facilitador, com competências em comunicação e observação, e com sentidos alertas para perceber os diferentes momentos de aprendizagem em que estão os envolvidos.

Importante destacar que as temáticas definidas também foram facilitadoras no processo de aprendizagem, e que a prática possibilitou uma avaliação positiva na construção do conhecimento relacionado a elas. O mesmo pode-se ressaltar para as estratégias do trabalho em grupo e dramatização, que além de favorecerem a aprendizagem, reforçaram sentimentos de valorização nos discentes, ao assumirem funções e papéis de outros, provocando significação no conhecimento.

É necessário refletir se, no processo de trabalho docente - atualmente, com inúmeras atividades em projetos de pesquisa, de extensão, de orientação, de participação em programa de pós-graduação 
(stricto e lato sensu), entre outras - podem ser disponibilizados tempo e energia para se construírem, efetivamente, práticas pedagógicas com o uso de metodologias participativas.

Uma reflexão importante é se todos têm opção de decidir ou escolher em participar de uma prática pedagógica mobilizadora. Inicialmente, percebe-se um recuo ou indecisão, seja dos docentes ou dos discentes. Sair do comodismo ou do conhecido requer mobilizações e mudanças, individuais e coletivas. É importante que os docentes acompanhem e motivem os discentes, e que estes, reciprocamente, façam o mesmo. Os discentes, questionados, no final, sobre seus sentimentos e percepções da prática, relataram que se sentiram incomodados e preocupados, no início, e, em determinados momentos, confusos. Entretanto, quando se debruçaram para construir relatórios, ampliar o estudo de caso, debater e, sobretudo, exercer as funções gerenciais, perceberam que, afirmativamente, apreenderam, e, por isso, sentiam-se seguros para iniciar a exercer estas funções nas atribuições do profissional enfermeiro.

A reflexão do contexto geral e final da prática educativa validou a permanente construção e reconstrução de saberes, que deve ser somatória e transformadora. Ao se acrescentarem novos conhecimentos a um anterior, permite-se reconhecer diferentes percepções da realidade e, a partir destas, associá-las e relacioná-las com conhecimentos teóricos que permitam entender um pouco mais a complexidade da organização social.

\section{Colaboradores}

Carmen Elizabeth Kalinowski planejou, organizou e conduziu as práticas, trabalhou na organização e análise dos dados, na redação e revisão final do texto; Reinaldo Miguel Dolny Massoquetti colaborou na revisão bibliográfica, organização dos dados, discussão e redação final; Aida Maris Peres e Liliana Müller Larocca colaboraram na redação e revisão final; Isabel Cristina Kowal Olm participou da discussão, análise dos dados e redação; Luciana Schleder Gonçalves participou do desenvolvimento das atividades, organização dos dados, discussão e redação final; Riciana do Carmo Calixto colaborou na revisão bibliográfica e revisão final do manuscrito.

\section{Referências}

BRASIL. Ministério da Saúde. Fundação Nacional de Saúde. Oficinas de educação em saúde e comunicação. Brasília: Ministério da Saúde, 2001.

FERREIRA, A.B.H. Mini-aurélio: o dicionário da língua portuguesa. 8.ed. Curitiba: Positivo, 2010.

LEAL, D.T.B.; NOVA, S.P.C.C. Métodos dramáticos aplicados a intervenções socioeducativas de autogestão e contabilidade. Educ. Pesqui. Contab., v.3, n.3, p.1-17, 2009.

LEITE, M.M.J.; PRADO, C.; PERES, H.H.C. Educação em saúde: desafios para uma prática inovadora. São Caetano do Sul: Difusão Editora, 2010.

MARTINEZ-RIERA, J.R. et al. Roleplaying en el proceso de enseñanza-aprendizaje de enfermería: valoración de los profesores. Cogitare Enferm., v.3, n.16, 411-7, 2011.

MOREIRA, M.A. A Teoria da Aprendizagem Significativa de Ausubel. In: (Org.). Teorias da aprendizagem. São Paulo: EPU, 1999. p.195. 
METODOLOGIAS PARTICIPATIVAS NO ENSINO ...

RODRIGUES, S. Roleplaying game e a pedagogia da imaginação no Brasil. Rio de Janeiro: Bertrand Brasil, 2004.

RUIZ-MORENO, L. Trabalho em grupos: experiências inovadoras na área de educação e saúde. In: BATISTA, N.A.; BATISTA, S.H. (Orgs.). Docência em saúde: temas e experiências. São Paulo: Senac, 2004. p.85-99.

SOUZA, M.M.T. A dramatização como recurso pedagógico na formação do profissional de saúde. Pró-univerSUS, v.1, n.1, p.1-10, 2010.

TAVARES, R. Aprendizagem significativa. Conceitos, v.5, n.10, p.55-60, 2004.

TEÓFILO, T.J.S.; DIAS, M.S.A. Concepções de docentes e discentes acerca de metodologias de ensino-aprendizagem: análise do caso do curso de Enfermagem da Universidade Estadual Vale do Acaraú em Sobral - Ceará. Interface - Comunic., Saude, Educ., v.13, n.30, p.137-51, 2009.

TOBASE, L.; GESTEIRA, E.C.R.; TAKAHASHI, R.T. Revisão de literatura: a utilização da dramatização no ensino de enfermagem. Rev. Eletron. Enferm., v.9, n.1, p.214-28, 2007.

VANNUCHI, M.T.O.; CAMPOS, J.J.B.A. metodologia ativa na residência em gerência do curso de enfermagem da UEL. Cogitare Enferm., v.12, n.3, p.358-64, 2007. 
O trabalho relata a experiência de docentes da área de administração e gerência em saúde no processo de construção e desenvolvimento de uma prática de aprendizagem significativa e participativa, desenvolvida no segundo semestre de 2010, com 23 estudantes de um curso de graduação em Enfermagem, na cidade de Curitiba-PR. As estratégias de trabalho em grupo e a dramatização na modalidade do role playing foram escolhidas por facilitarem a participação e a motivação para a aprendizagem. $O$ sistema de saúde, planejamento em saúde e funções gerenciais foram temáticas definidas para compor a prática. O aprendizado permitiu o exercício das funções gerenciais em uma situação real, concreta e com significados a todos, e, ainda, o destaque das docentes sobre a construção de práticas de aprendizagem com metodologias participativas, que requerem tempo, motivação, dedicação e comunicação, mas, sobretudo, a mudança do processo de trabalho.

Palavras-chave: Educação em enfermagem. Metodologia participativa. Administração e gerenciamento em enfermagem.

\section{Participative methods in teaching administration within nursing}

This paper reports the experience of teachers within the field of healthcare administration and management in the process of building and developing practices of participative and meaningful learning, which took place in the second semester of 2010, with 23 students in an undergraduate nursing program in the city of Curitiba, Paraná. Strategies for group work and dramatization through role playing were chosen, since these facilitate participation and motivation for learning. The healthcare system, healthcare planning and managerial functions were the themes defined for constituting the practice. The learning experience allowed managerial functions to be performed in a real and concrete situation, with meaning for all participants. The teachers' role in constructing learning practices was highlighted, with participative methods that required time, motivation, dedication, communication and, especially, changes to their work processes.

Keywords: Nursing education. Participative methods. Administration and management in nursing.

\section{Metodologías participativas en la enseñanza de la administración en enfermería}

El trabajo relata la experiencia de docentes del área de administración y gestión en salud en el proceso de construcción y desarrollo de una práctica de aprendizaje significativa y participativa, desarrollada en el segundo semestre de 2010, con 23 alumnos de un curso de graduación en Enfermería, en la ciudad de Curitiba, Estado de Paraná. Se eligieron las estrategias de trabajo en grupo y la dramatización en la modalidad de role playing porque facilitaban la participación y la motivación para el aprendizaje. El sistema de salud, planificación en salud y funciones de gestión en una situación real, concreta y con significados para todos, y también el destaque de las docentes sobre la construcción de prácticas de aprendizaje con metodologías participativas que requieren tiempo, motivación, dedicación y comunicación pero, sobre todo, el cambio del proceso de trabajo.

Palabras-clave: Educación en enfermería. Metodología participativa. Administración y gestión en enfermería. 
